\title{
Explaining the "Accuracy" of Proxy-Reports on Attitudes towards Immigrants in Germany. Two Approaches Compared
}

\author{
Angela Jäger ${ }^{1}$
}

\begin{abstract}
The paper analyzes the degree to which subjects are able to "accurately" report the attitudes of their reference group or close discussion partners. Studies using a social network approach have found evidence for a strong association between the respondents' own attitude reports and their reports on the perceived attitudes of relevant others. Since most research has not tested whether this perception of ego is congruent with the actual attitudes of the alters, it remains unclear to what degree the observed correlations are substantiated in social influence processes or simply result from egos' projection of their own attitudes on their alters. However, descriptive statistics have confirmed that proxy-reports and self-reports with regard to attitudes reveal a relatively low degree of congruence.

In this study, the influence of ego's access to information on the "quality" of the proxy-reports concerning attitudes towards immigrants in Germany is analyzed in the context of a broader understanding of the congruence of proxy-reports. For this purpose, we use two approaches that apply different criteria of validity to assess the "accuracy" of proxy-reports on attitudes on an individual level. In order to address our questions, we reanalyze recently collected data $(\mathrm{N}=1.693)$ on egos' attitudes towards immigrants, including information about egos' perception of alters' attitudes and alters' self-reports on the same matter.

According to our results stemming from multivariate two-level regression models, the accuracy of proxy-reports is conditional on characteristics of the dyadic relationships as well as the complete network in which these dyads are embedded, a fact which apparently has not yet been considered in previous research. In summary, it is recommended that for the collection of attitudinal data by means of proxy-reports the name interpreter items should refer to general dispositions rather than to specific attitudes of alters.
\end{abstract}

\footnotetext{
${ }^{1}$ University of Mannheim, Mannheim Centre for European Social Research (MZES), D-68131 Mannheim, Germany; ajaeger.mzes@web.de
} 


\section{Introduction}

The analysis of social networks has become an important part of social science research mainly because it provides the possibility to include the social embeddedness of actors in the description and explanation of sociologically interesting phenomena. Egocentric network studies have become especially prominent, since they can be attached well to general social survey techniques. This paper deals with the quality of measurements of characteristics of network members concerning egocentric networks. We address the question of the degree to which subjects are able to "accurately" report the attitudes of their reference group or close discussion partners, and how this "accuracy" can be assessed and explained.

In contrast to complete networks, egocentric networks consist of a focal actor, called ego, and a set of other individuals, called alters, with whom ego is related in a certain way. Members of the network are defined by their relations to ego (cf. Laumann et al., 1989). The ties among the alters are measured as well (Wasserman and Faust, 1994; Wellman 1988). The typical procedure to obtain egocentric network data is to interview respondents on their personal reference settings. Via one or more name generators, the respondents designate relevant alters, afterwards, via name interpreters, the respondent reports on several attributes of the persons nominated, on the properties of her/his relationship to each alter, and, finally, on the intensity of ties among the alters themselves.

Thus, with respect to the actual characteristics, the "accuracy" of ego's reports determine the validity of the information on the attributes of her/his alters and the relational structures of the network. The data obtained by asking ego can only reflect ego's point of view, whereby the actual characteristics of the alters and the relations among them could be different. However, especially when analyzing the influence of attitudes and opinions of important discussion partners on the attitudes of actors, it is necessary to distinguish between the perceived features of alters reported by ego and their actual characteristics. Therefore, it is necessary to pay particular attention to the "accuracy" of proxy-reports on alters' attitudes.

The aim of this study is to analyze the conditions under which ego reports alters' attitudes towards immigrants in Germany in the same way that alters would report on their own attitude towards this topic. The focus lies on the influence of ego's access to information. Additionally, attention will be directed to the limits of congruence analysis. Constraints are detected with respect to assessing the extent to which the proxy-reports are based on self-anchoring heuristics and to the identification of relevant indicators of the exchange of attitudinal information.

For this purpose, we use two approaches that apply different criteria of "accuracy" to assess the "accuracy" of proxy-reports on attitudes. First, we analyze the congruence between ego's reports on alters' attitudes and the corresponding 
self-reports of alters. Following a second approach, we examine to what extent the proxy-report on alter's attitude can be explained by alter's actual attitude or by ego's own attitude. In both approaches, the multivariate models are estimated on an individual level referring to each specific proxy-report; due to the hierarchical structure of egocentric network data, multilevel estimation procedures are used.

In order to address these questions, we reanalyze data of the project "Ethnic Cleavages and Social Contexts" collected in Germany in 2002. Besides egos' attitudes towards immigrants, it contains information on egos' perceptions of alters' attitudes and alters' self-reports in this respect $(\mathrm{N}=1.693)$. The "accuracy" of two proxy-reports dealing with preferences on immigration of specific groups will be investigated. In this study, egocentric networks are defined as personal "core discussion networks" (Marsden, 1987), consisting of persons with whom a respondent has "discussed important matters" (Burt, 1984).

We first address the theoretical background of the "accuracy" of proxy-reports; the focus, here, lies on the determinants of ego's information accessibility to alter's attitudes. Then, two ways of assessing the quality of ego's reports on alter's attitudes on an individual level are introduced. Finally, the empirical results of both approaches are presented and discussed. The results show that the "accuracy" of proxy-reports depends on characteristics of the dyads as well as of the complete network in which these dyads are embedded. In summary, it is recommended that for the collection of attitudinal data by means of proxy-reports the name interpreter items should refer to general dispositions rather than to specific attitudes of alter.

\section{The "accuracy" of proxy-reports}

The extent to which proxy-reports represent useful information on ego's personal reference setting is of fundamental importance for the use of (egocentric) network data. For the sake of distinguishing reports on oneself from reports on others, the first are called self-reports and the latter proxy-reports (e.g. Moore, 1988: 156; Sudman et. al, 1996: 227). Descriptive statistics have confirmed that proxy-reports and self-reports reveal a relatively low degree of congruence, especially with regard to attitudes. Therefore, correlations between ego's attitudes and the attitudes of her/his alters that are reported by ego can only be interpreted adequately if it is tested whether ego's perception is congruent with the actual attitudes of the alters. Otherwise, they have to be treated exclusively as ego's perceptions (Pappi and Wolf, 1984; cf. Kreuter, 2004; Rice and Aydin, 1991; White and Watkins, 2000). 


\subsection{Previous research}

Despite the essential relevance of the quality of proxy-reports, the basis for the assessment of reports on traits of people important in a person's life proves to be remarkably weak (cf. Chen, 1999; Moore, 1988). In addition, various criteria for quantifying the "accuracy" of ego's proxy-reports on traits of alters have been used, each highlighting different research interests in the validity or reliability of name interpreters and concerning different kinds of proxy information (cf. Marsden, 1990).

There is still little research on the individual level measured by comparing alter's self-report and ego's proxy-report for each dyad, especially as far as network data and attitudinal items are concerned. Moreover, only a small amount of systematic theoretical work has been conducted on the determinants of the congruence between ego's proxy-report and alter's self-report (cf. Marsden, 1990; Pappi, 1998; Sudman et al., 1996). Previous research has primarily focused on the constraints of proxy-reporting, examining the underlying cognitive processes of perception, information storage, and information retrieval (cf. Schwarz and Wellens, 1994; Sudman et al., 1996; Tourangeau et al., 2000). Accordingly, in contrast to reports on oneself, proxy-reports are for the most part based on a lesser amount of information. Furthermore, proxy-reporters differ in their relative social distance to the information in question, so that biasing processes could have different aims (cf. Skowronski et al., 1994; Sudman et al., 1996; White and Watkins, 2000). Finally, proxy-reports rely on dispositional information to a higher degree than self-reports. Schwarz and Wellens (1994) suggest that information on attitudes of other persons are more likely perceived as caused by a general disposition than as related to a specific attitude-object. Moreover, memory is considered as hierarchically organized, so that less effort is needed to form proxy-reports using general impressions than to search for specific information on the attitudes of relevant reference persons (cf. Conway, 1992).

Consistent empirical evidence of the causes of different accuracy levels have only been found for two indicators of information accessibility: Visible traits as sociodemographic characteristics are reported more accurately, and discussions related to the respective attitudes or behavior mostly enhance the probability of congruence. However, the relevance of the strength of the ties between ego and alter has not been confirmed (e.g. Bickart et al., 1994; Chen, 1999; Kojetin and Mullin, 1995; Menon et al., 1995; White and Watkins, 2000). Some studies have also been conducted to characterize the cognitive processes and heuristics used in constructing proxy-reports. The findings based on thinking-aloud protocols contradict the longstanding assumption that biases of proxy-reports result mostly from egos' projection of their own attitudes onto their alters. The results suggest that the incongruence between egos' proxy-reports and alters' self-reports is caused less by self-anchoring processes than expected (e.g. Chen, 1999; Sudman et al., 1996; Todorov and Kirchner, 2000). 


\subsection{Assessing and explaining the "accuracy" of proxy-reports}

In this study, "accuracy" is understood as the validity measured for each dyad by the criteria that ego's reports on attitudes of her/his reference persons are congruent or at least highly correlated with what the alters themselves would answer. Each proxy-report is assessed relative to the answer of a specific alter. We consider this dyadic level to be required because in substantive research on social networks individual proxy-reports are often used for calculating important network features, such as homogeneity, and for assessing the relationship between ego and different alters.

Our study is based on the theoretical assumption that congruence between ego's report on alter's attitude and the corresponding self-report of alter results from two answering processes which differ in the respondent's report status in respect to the information in question. Accordingly, ego's access to information on alter's attitude will have a high influence on the congruence.

Therefore, two kinds of processes have to be taken into account to explain congruence. First, congruence could be explained by processes which determine the probability that ego has access to and interest in relevant information. So, the question is under which conditions it is more probable that ego learns of alter's attitudes. In general, information can be obtained in two ways: knowledge of reference persons can be based on direct information exchange between ego and alter, or information about alter can be transmitted via other persons - a fact which seems to have not yet been considered in research on the "accuracy" of proxyreports. With respect to both kinds of information accessibility, it can be presumed that if ego has more access to relevant information concerning alter's attitude, it is more probable that ego's proxy-report will rely on specific knowledge of alter's attitude, and, as a result, the probability of a congruent report should increase (Sudman et al., 1996; Tourangeau et al., 2000).

Second, congruence should be explained by referring to both answering processes, while paying special attention to the situation of proxy-reporting. The purpose of considering these processes is to ensure that the influence of determinants of information accessibility can be identified separately from other factors. This is only possible if congruence is based on two "substantive" answers which both rely on information about alter's attitude. However, congruence can also result from "random" congruent reports based on biased responses. At least in the case of non-attitudes, self-reports could be biased (e.g. Stocké, 2003). Nevertheless, proxy-reporting, in particular, is more susceptible to response effects because proxy-reports typically require more effort to search for relevant information. Less motivated and uncertain interviewees will not invest much in the complex and effortful process of memory retrieval. Thus, their proxy-reports will be less accurate. 


\subsection{Hypotheses}

In the following analyses, the focus lies on ego's access to information. It essentially determines the amount of relevant information ego can store and later recall for constructing proxy-reports. It should therefore affect the probability that the proxy-report is congruent with alter's self-report.

Since attitudes are not directly observable, a certain effort to exchange, capture, and recall relevant information has to be made, depending on the salience of the attitude and its importance for the relationship. A variety of factors may be related to how much one person can learn about the attitudes of her/his reference persons. In this study, we examine three hypotheses.

On the one hand, knowledge of reference persons can be based on direct information exchange between ego and alter. It can be assumed that the amount of information available is related to the amount of time that ego and alter spend talking about topics concerning the attitude in question. Additionally, it is assumed that more information is retained if ego pays much attention to the issue. Therefore, hypothesis 1 suggests that proxy-reports on alter's attitudes towards immigrants will more likely be based on alter's actual attitudes and will therefore be more likely congruent with alter's self-reports in this respect, if ego discusses topics concerning aspects of attitudes towards immigrants with alter, especially if "immigrants in Germany" is a relevant topic for ego.

Furthermore, the opportunities to obtain information about alter's attitudes based on direct information exchange between ego and alter can be operationalized by the characteristics of the respective relationship. According to the assumption that information on political and social attitudes are a by-product of everyday contact (Pappi, 1996), frequent contacts should provide more opportunities to gain knowledge of alter's attitudes towards immigrants. But, in regard to core networks the advantage of frequent contacts should be minimal for "very close" ties which are assumed to provide a greater variety of information accessibility than "not so clos" ties. ${ }^{2}$ Therefore, it is expected that the influence of the frequency of contact will only be considerably detected for contacts which are classified as "not so close". ${ }^{3}$ Hypothesis 2 predicts that proxy-reports on alter's attitudes towards immigrants will be based more likely on alter's actual attitudes and therefore will more likely be congruent with alter's self-reports in this respect, if ego has more

\footnotetext{
${ }^{2}$ Also within core networks, "not close" ties are typically characterized by specialized and less intimate communication; attitudes towards immigrants can neither be assumed to be generally relational relevant nor typically salient in these ties. Thus, regarding looser ties only under the condition of daily conversations, ego will probably receive insights in alter's opinions in this respect. By contrast, for "very close" ties the additional advantage of frequent contacts should be minimal (cf. Erickson, 1988: 103).

${ }^{3}$ Besides that, closeness is considered of no further relevance to operationalize information accessibility because it is a multidimensional indicator. Apart from information accessibility it also reflects social distance, which can be a cause for different susceptibility to response effects like social desirability.
} 
frequent contacts to alter and simultaneously ego's relationship to alter is less close. A moderating effect including both indicators is expected.

On the other hand, structural features of the network in which the ego-alterrelation is embedded will affect ego's opportunities to access information about reference persons. Under certain circumstances, other members of the network can be valuable sources of knowledge of alter's attitudes and opinions. We consider density and attitudinal homogeneity as the most important characteristics in this respect.

Very dense networks provide the opportunity for a high degree of information exchange among the alters. Consequently, ego has the possibility to indirectly access information (cf. Erickson, 1988: 108). Furthermore, ego can probably validate her/his knowledge of a certain alter according to other alters, so that misperceptions should be less probable; ego can also be expected to feel more secure about her/his perceptions. ${ }^{4}$ With regard to the attitude in question, actual homogeneous networks can be considered relevant for proxy-reporting in three ways. First, a homogeneous network facilitates the perception of alter's attitudes. By communicating with a variety of persons, ego has greater access to different dimensions of a certain attitude. Second, a vague perception of a group norm can serve as an anchor for constructing proxy-reports. In homogeneous networks, this strategy is more likely to deliver congruent answers. Finally, it can be assumed that an issue will be less relevant for the ties if the network is heterogeneous in regard to it. According to both assumptions, hypothesis 3 suggests that proxyreports on alter's attitudes towards immigrants will more likely be based on alter's actual attitudes and therefore will more likely be congruent with alter's selfreports in this respect, if ego and alter are related in a network which is dense and/or actually homogeneous with regard to the attitude in question.

\subsection{Two approaches to identify relevant determinants concerning ego's information accessibility}

One way to assess the "accuracy" of ego's proxy-reports on an individual level is to compare these reports with the self-reports of each alter. "Accuracy" in this case is understood as the validity of proxy-reports measured by the congruence with alter's self-reported attitude. By computing the difference between both reports, the amount of congruence can be calculated. Thus, the dependent variable for further analyses is also provided. (cf. Kojetin and Mullin, 1995).

\footnotetext{
${ }^{4}$ It has to be emphasized that these assumptions of a higher information accessibility indicated by the density are related to the accuracy of all proxy-reports. Without referring to specific alters, the qualifications of this bridge hypothesis are only fulfilled by very dense networks. Because no distinctions between certain alters are considered, density can not be operationalized as continuously increasing the accuracy.
} 


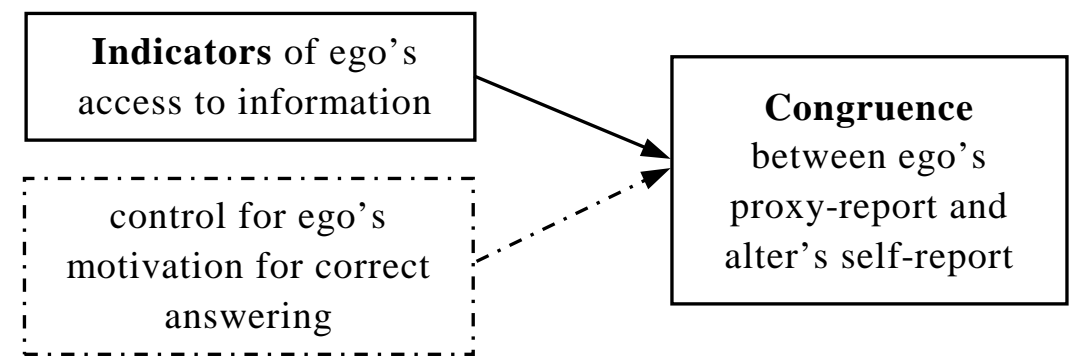

Figure 1: Explaining congruence.

Using this measure the impact of ego's access to information on the congruence can be tested. As is shown in Figure 1, the direct and indirect effects of various indicators of ego's opportunities to access information, while controlling for ego's motivation to answer correctly, are be estimated. An advantage of this approach is that many determinants can be considered. Moreover, it is easy to model the assumed moderating effects between the indicators of direct information exchange. According to our hypotheses, the influence of direct information exchange based on "discussions" should be reinforced by the attention that ego gives to the topic. Therefore, a moderating effect is tested concerning hypothesis 1. Similarly, as regards hypothesis 2, the closeness of the tie should moderate the positive impact of the frequency of contact.

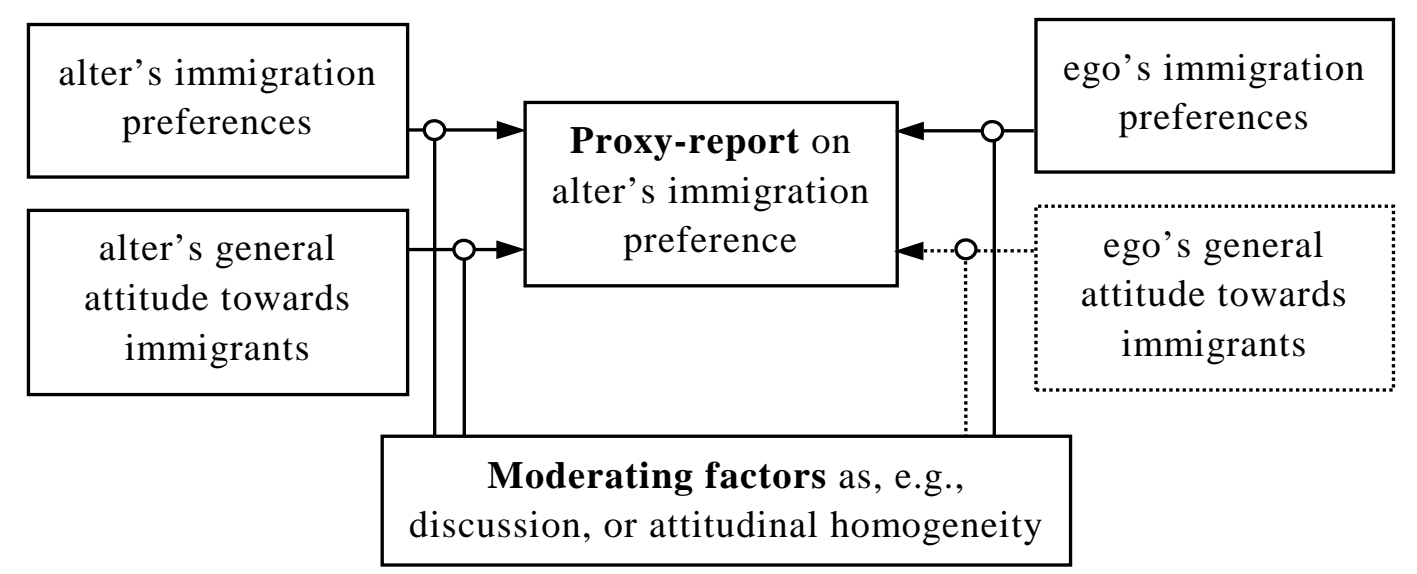

Figure 2: Explaining proxy-reports.

Another way to assess the "accuracy" of ego's proxy-reports on an individual level is to analyze the extent to which the proxy-reports can be explained by ego's own attitudes or by the actual attitudes of alter (e.g. Pappi and Wolf, 1984). At this point, no clearly defined criteria for assessing the "accuracy" of proxy-reports can be used. Nevertheless, the conditions under which proxy-reports on attitudes reflect alters' attitudes or dispositions to a greater extent and don't simply result 
from egos' projections of their own attitudes can be examined. In this case, the proxy-reports are considered as the dependent variables, as displayed in Figure 2.

The advantage of this approach lies in the possibility of separating the impact of general and specific attitudes. Thus, a specific problem of proxy-reports on attitudes can be addressed: Proxy-reports could rely on ego's knowledge of alter's specific attitude, as well as on utilizing other information, such as attitude-related general dispositions of alter. In both cases, proxy-reports don't simply result from egos' projections of their own attitudes, but reflect alters' own attitudes.

The influence of ego's access to information can be captured as moderating effects. According to our hypotheses, we assume that these moderating factors will affect the impact of alter's attitudes on the proxy-reports. However, due to the model structure the number of indicators considered is limited, because each factor requires four additional interaction variables. Additionally, the expected interaction effects can't be directly tested. As an approximation, the dyads are grouped according to the hypotheses.

\section{Data and measures}

\subsection{Sample and data}

For our analyses, we use data from the project "Ethnic Cleavages and Social Contexts" collected in Germany in 2002. The main objective of this research project was to explore contextual effects of the diverse manifestations of social distance on the part of Germans towards ethnic minorities (cf. Becker, 2005; Ganter, 2003). Particular attention was paid to the social embeddedness of such attitudes and behavioral intentions in social networks and primary groups. Information about personal contexts was gathered via egocentric networks. Reference persons were identified by the name generator proposed by Burt (1984) which was additionally preceded by a number of introductory questions on social contacts in different spheres of activity. The sequences of the name interpreters were organized question-wise instead of alter-wise. ${ }^{5}$

The survey design of this project contained a regionally limited, multilevel snowball sampling based on egocentric networks (cf. Jäger, 2004). The particularity of the survey design was that respondents were not only asked for reports on characteristics of the alters but also for contact information. In line with the survey design, 2,010 standardized telephone interviews were conducted, among

\footnotetext{
${ }^{5}$ Question-wise means that every question for a characteristic of alters had to be answered for all nominated persons before the next characteristic was asked for, going question by question until the end of the network part of the questionnaire (Kogovšek et al., 2002: 3f.).
} 
them, 825 interviews with randomly selected persons and 1,185 follow-upinterviews with nominated persons. ${ }^{6}$

The resulting dataset for our analyses contains 1,693 ego-alter-dyads based on 892 ego-networks. ${ }^{7}$ Each dyad represents a relationship between one ego and one alter. In comparison with all relations nominated by respondents the dyads in the analysis are slightly, but significantly different. They represent more frequent, multiplex, close, longer continuing contacts within denser networks.

The data is hierarchical because egos chose different alters according to the name generator and reported about them. Thus, egos' proxy-reports about these persons as well as the corresponding alters' self-reports are not statistically independent observations but nested into egos' networks. ${ }^{8}$ Such a nested data structure requires at least a two-level analysis. At the bottom of the hierarchy, the first level captures each dyad (micro unit), including the specific relationship between one ego and one alter as well as the dependent variable of the analyses. The second level at the top of the hierarchy captures each ego (macro unit), including the structure of her/his network (Ganter, 2003: 198-201; Goldstein, 1995; Snijders and Bosker, 1999). ${ }^{9}$

Using this survey design, data was provided which allowed a validation of the proxy-reports on alter's attitudes by comparing them with alter's self-reported attitudes. The data include egos' attitudes towards immigrants, information about egos' subjective perception of alters' attitudes towards immigrants and alters' selfreports in this respect. Additionally, it contains proxy information about the relationship between ego and alter and the whole personal network, as well as self-reports of ego and alter on socio-demographic characteristics and political attitudes.

\footnotetext{
${ }^{6}$ The sampling process was started with four local initial samples, randomly selected from the adult population of German cities holding German citizenship by birth. As far as possible, all nominated alters were interviewed in follow-up interviews. Again, the nominated persons of these interviews were interviewed as well, and so on; they formed also initial points for further egocentric networks. The snowball sampling process (cf. Goodman, 1961) was restricted in two ways. First, only alters who were part of the basic population were asked for their core network so that they could form initial points for the next stage of the sampling process. The other alters only had to answer questions about themselves. Second, the sampling process was stopped after the eighth stage.

${ }^{7}$ Due to the defined boundary specifications of the snowball sampling in total 1,663 (out of 2,010) interviewed persons were asked for their personal networks. Among them 1,551 persons nominated at least one alter. After controlling for the definitive identification of the alters and including the multiple nominated persons the resulting dataset contains 1,693 ego-alter-dyads based on 892 ego-networks and including 1,300 different alters. These dyads combine interviews with 324 randomly selected persons and 1.180 follow-up-interviews (cf. Jäger, 2004).

${ }^{8}$ For instance, the ego-alter dyads include for 217 egos at least three dyads. Dyads in respect to all nominated persons are included in the data for 103 egos. On average there are 1.89 followup interviews per ego, ranging from $1(\mathrm{~N}=412)$ to $5(\mathrm{~N}=15)$.

${ }^{9}$ The particularity of a two-level model as a kind of multilevel model is that the estimations consider both the variance of the outcome variable at the 'between-network' level and the variance at the 'within-network' level (all dyads of one ego). Besides, two-level models presume that the units of the first level represent a random selection of all micro units of each macro unit (Snijders and Bosker, 1999: 208). This assumption could be discussible with respect to our data.
} 


\subsection{Measures}

Two items are used to analyze the "accuracy" of ego's proxy-reports on alter's attitudes towards immigrants. They asked for alter's preferences on immigration, first concerning "Ethnic German immigrants from Eastern Europe" (F99) and second "Asylum-seekers" (F100). These two items are part of a four-item index of preferences on immigration, which has been used several times in the German General Social Survey (ALLBUS) (Wasmer et al., 1996; e.g. Harkness and Haarmann, 2004). The answer scale included three categories labeled in the sense that immigration should be "unrestrictedly possible (1), "restricted"(2), or "completely stopped"(3) for those people.

For both ego and alter, the actual attitudes towards immigrants were measured in two ways. First, the abovementioned full index of preferences on immigration was used (F72-F75). The answers were coded according to the same categories as the proxy-reports. Second, another four-item index was used measuring the agreement with discriminating statements on immigrants in general (F47) (cf. Alba et al., 2004). All relevant questions are listed in Appendix A.

The dependent variables are defined on the basis of these items. On the one hand, the two proxy-reports can be compared with the identical items answered by alters as self-reports. Thus, the congruence measured as the dichotomized difference can be analyzed for each proxy-report. Additionally, it is examined to what extent each proxy-report can be explained by the actual attitudes reported by ego and alter. These attitudes are quantified using both attitudinal indexes, mentioned above.

Both analyses focus on the influence of ego's information accessibility. At the dyadic level, four factors concerning ego's opportunity to obtain information on alter's attitudes towards immigrants are taken into account:

- General discussion (dichotomous): If ego reported to have discussed with alter the "relationship between Germans and foreigners" during the last six months, the indicator is set to 1 ; otherwise, it is set to 0 (F98).

- Very relevant topic - ego (dichotomous): Among different topics, ego had to score the importance of the topic "immigrants" regarding her/his place of residence. The answer "very relevant" is coded 1; the others, "relevant", "less relevant", and "non-relevant", are coded 0 (F12_C).

- Weekly contact (dichotomous): If the value is 1 , this variable indicates that during the last six months ego and alter have communicated with each other at least once a week; otherwise, it is coded 0 (F97).

- Very close relationship (dichotomous): If ego scored the relationship with alter as "very close", the indicator takes on the value 1 . Whereas, if ego labeled the relationship as "close" or "not so close", it is coded 0 (F95). 
Additionally, two indicators for ego's information accessibility are included which refer on the underlying structure of the network in which ego's relation to alter is embedded:

- Very dense networks (dichotomous): This indicator distinguishes between above-average dense networks (1) and looser connected networks (0). The cut-point was a weighted density ${ }^{10}$ greater than 1.5 implying that according to ego the greater part of alters know each other well. Besides substantial reasons, the dichotomous coding was chosen because of the problematic correlation between density and net size and the resulting uncertainty about the meaning of values between both extreme points (cf. Barnes, 1979; Scott, 1991: 72-79). An associated missing dummy indicates networks with less than two nominated alters $(\mathrm{N}=31)$ for which density could not be computed; thus, these cases remain in the analyses.

- Homogeneity of ego's network concerning actual attitudes (continuous): Considering the self-reports of alters with regard to the index of preferences on immigration, the proportion of attitudinal homogeneous dyads among the alters of each network was computed. A difference of less than 0.51 between the self-reports of alters is categorized as homogeneous. The indicator may take on values between 0 (maximal heterogeneity) and 1 (maximal homogeneity). An associated missing dummy indicates networks with less than two corresponding self-reports $(\mathrm{N}=417)$.

Besides the indicators of ego's access to information mentioned above, several control variables are included in the analyses of the congruence between ego's proxy-reports and the actual alters' self-reports. First, net size and the number of follow-up interviews are included because these two features of the network are correlated with the explanatory variables which refer to the whole ego-network. Second, it is controlled for the perceived attitudinal homogeneity of ego's network, which is calculated like the actual attitudinal homogeneity using the average of both proxy-items. Third, the relevance of the topic reported by alter, measured like the corresponding variable for ego, is included. Fourth, it is controlled for the duration of relationship between ego and alter (F93) as an additional characteristic of the tie.

Finally, three indicators for ego's motivation to answer correctly are included in the analyses. Thus, it can be shown that the influence of ego's information accessibility has an effect even after controlling for these determinants. First, the variable false telephone number(s) indicates that the interviewee consciously reported inaccurately instead of refusing to answer. If the respondent gave false

10 Density of egocentric networks measures the proportion of actual relationships between alters (F102) in comparison to the potentially possible ones. Weighted density additionally takes into account ego's perception of the familiarity among the alters (F103). This network feature varies from 0 meaning "all alters don't know each other" to 2 meaning "all alters know each other well". 
contact information for at least one alter, the value is 1 . The variable can be interpreted as the willingness to answer incorrectly, at least when reporting on alters. Second, a dummy variable indicates whether ego refused to respond to "sense of nationality". This can be regarded as a low motivation to answer with respect to the topic. Third, the nomination rank of alter reflects the methodological fact of a question being repeated and indicates a question order effect insofar as the name interpreters are organized question-wise. ${ }^{11}$ According to the order in which persons were listed, the first nominated alter was given value 1 , the second value 2 , and so on.

\section{Results}

\subsection{Congruence measured}

The overall distributions of the perceived preferences on immigration of Ethnic Germans or Asylum-seekers as well as alters' corresponding actual opinions are displayed in Table 1. On average, the data according to both report statuses show only slight differences. Both distributions have a high kurtosis.

Table 1: Distribution of both proxy-reports and the corresponding self-reports of alter.

\begin{tabular}{llcccccccc}
\hline Item & Report & \multicolumn{4}{c}{ Answer categories (\%) } & \multicolumn{5}{c}{ Distribution measures } \\
& status & $(1)$ & $(2)$ & $(3)$ & M & Var. & Skew. & N & NonR \\
\hline Ethnic & Proxy & 22.17 & 70.61 & 7.22 & 1.85 & 0.27 & -0.17 & 1579 & 6.73 \\
Germans & Alters & 21.10 & 73.76 & 5.14 & 1.84 & 0.24 & -0.37 & 1673 & 1.18 \\
\hline Asylum- & Proxy & 28.66 & 65.29 & 6.05 & 1.77 & 0.30 & -0.09 & 1570 & 7.27 \\
seekers & Alters & 27.59 & 68.71 & 3.69 & 1.76 & 0.26 & -0.32 & 1678 & 0.89 \\
\hline
\end{tabular}

Notes: Answer categories: (1) unrestricted, (2) limited, (3) stopped.

Distribution measures: M: Mean; Var.: Variance, Skew.: Skewness, N: number of answers, NonR: proportion of item-non-response relative to the total number of dyads (1.693).

According to our data, the majority prefers a limited immigration of both groups; though, slightly less in respect of Asylum-seekers. Concerning both items, the overall distribution of proxy-report and alter's answer is nearly the same. One slight difference can be discerned in the proportion of extreme positions, which is

${ }^{11}$ For instance, Kogovšek et al. (2002) found empirical evidence for the impact of question order effects on the accuracy of proxy-reports. In contrast to that, some studies used the nomination rank as an indicator of the intensity of the relationship between ego and alter. This interpretation is supported by the fact that ego's relationship to first nominated persons is typically characterized by more frequent contacts and a higher degree of emotional closeness compared to later nominated relationships. (cf. Pfenning et al., 1991; Pappi, 1998). However, controlling for the characteristics of the relationship between ego and alter, the methodological dimension of the nomination rank should be captured. 
less frequent for self-reports than for proxy-reports. The variance is, therefore, slightly lower for answers of alters. A more important difference between both report statuses is - as expected - the higher amount of item-non-responses for ego's proxy-reports, especially with regard to the second item on the immigration of Asylum-seekers.

In contrast to that finding, the direct comparison expressed by the difference between ego's proxy-report and alter's self-report computed for each dyad - as far as both reports were available - shows another picture. As can be seen in the bold column of Table 2, only about six of ten dyads are congruent when compared on the individual level. The proportion of congruent dyads is significantly lower in regard to the second proxy-item. Nevertheless, high discrepancies between both reports are rare; differences of more than one scale unit are observed only in one out of a hundred dyads; a significant trend in the direction of misjudgments cannot be detected.

Table 2: Differences between ego's proxy-report and the corresponding self-report of alter and Cohen's Kappa coefficients (for both items on alter's preferences on immigration).

\begin{tabular}{lcccccccc}
\hline Item & \multicolumn{4}{c}{ Differences (frequency in \%) } & \multicolumn{2}{c}{ Interrater agreement } & $\mathrm{N}$ \\
& -2 & -1 & $\mathbf{0}$ & 1 & 2 & $\mathrm{k} \mathrm{(z)}$ & $\mathrm{k}_{\mathrm{w}}(\mathrm{z})$ & \\
\hline Ethnic Germans & 0.6 & 17.2 & $\mathbf{6 2 . 9}$ & 18.7 & 0.6 & $0.13(6.41)$ & $0.16(7.92)$ & 1.564 \\
Asylum-seekers & 0.5 & 20.3 & $\mathbf{5 6 . 8}$ & 21.8 & 0.6 & $0.08(3.77)$ & $0.11(5.29)$ & 1.557 \\
\hline
\end{tabular}

Notes: $\mathrm{k}$ : Cohen's Kappa, unweighted; $-\mathrm{k}_{\mathrm{w}}$ : Cohen's Kappa, weighted using factors $1 / 0,5 / 0$; $\mathrm{z}$ : corresponding $\mathrm{z}$-statistic testing Kappa $<>0$

This overview of the degree of congruence gives a first impression of the quality of the proxy-reports. However, it does not allow an assessment of whether the relation between both reports are caused only randomly. An interviewed person who answered the questions for each nominated person by thoughtlessly placing her/his score in the mid-category has a high chance of being in congruence with at least three alters, due to the marginal distribution of the items.

A measure of congruence which considers the effects of the number of answer categories and their different distributions is the Kappa coefficient, an index of inter-rater reliability introduced by Cohen (1960). As can also be discerned in Table 2, according to the criteria laid out by Landis and Koch (1977: 165), the non-weighted Kappa coefficients of 0.13 regarding the item on Ethnic Germans and 0.08 regarding the second item indicate only a "slight" relation between proxy- and self-reports. ${ }^{12}$ As the weighted Kappa coefficients show, this judgment remains the same, also after controlling for the extent of the differences; it can

\footnotetext{
${ }^{12}$ Landis and Koch (1977) proposed the following scale to describe the degree of congruence referring to Cohen's Kappa coefficients: "poor" $(<0,0)$, "slight" $(0,00-0,20)$ "fair" $(0,21-0,40)$, "moderate" $(0,41-0,60)$, "substantial" $(0,61-0,80)$, "almost perfect" $(0,8-1,0)$.
} 
also be compared with results of other studies on the congruence of proxy-reports on attitudes (e.g. Chen, 1999: 13ff.; Kojetin and Mullin, 1995: 1112f.; White and Watkins, 2000: 343f.).

In summary, the degree of congruence for both attitudinal items is not far from the randomly expected degree, but, according to the corresponding z-statistic, all coefficients significantly differ from zero. This means that ego's reports on alters' attitudes were not random answers, but instead, to a certain degree, referred to a specific alter. ${ }^{13}$ The reference to the specific alter is also confirmed by the positive correlation between both calculated differences (Kendall's tau-b=0,281). In reference to the amount of congruent proxy-reports, both congruence measures are positively correlated, as well $(\mathrm{OR}=2,20, \mathrm{z}=7,29)$.

\subsection{Congruence explained}

In the following analyses, the congruence between ego's perception of alter's attitude and alter's actual attitude is measured as a dichotomous outcome. A dyad is scored as congruent if both reports are the same; otherwise, it is labeled as noncongruent. This measurement level is appropriate, because the underlying items have a relatively low variance, and high discrepancies between proxy-reports and corresponding self-reports are rare. Furthermore, looking at the Kappa coefficients, the extent of the differences does not change the grading of the relations between both report statuses.

The results of the two-level random intercept logistic regression models for both questions are presented in Table 3, in which only the relevant coefficients concerning the influencing factors of ego's opportunities to gain access to information are listed. Both models are significantly different than the empty models ${ }^{14}$, but by contrasting the estimated model parameters it is obvious that the used model is less suitable to explain the congruence of the second proxy-report on alter's preference on immigration of Asylum-seekers. This is possibly caused by the fact that ego's responses to the second proxy-item are formed in a less specific way in regard to the respective alters. Accordingly, information accessibility has less influence on the congruence of this proxy-report. Supporting this argument, the average ranges of all proxy-reports referring to Asylum-seekers within a network as well as the corresponding average standard deviations are

\footnotetext{
13 The comparison with the corresponding coefficients based on two proxy-reports on sociodemographic features shows - as expected - that the respondents can report on salient traits much more accurately. According to the corresponding kappa coefficients, the relation between both reports on alter's age can be called "moderate" $(\mathrm{k}=0.51 ; \mathrm{z}=146,87)$ or even "almost perfect" when regarding the amount of the discrepancy $\left(\mathrm{k}_{\mathrm{w}}=0.96 ; \mathrm{z}=66,24\right)$. The reports on alter's educational level are "substantially" related $(\mathrm{k}=0.67 ; \mathrm{z}=37.28)$, also after controlling for the extent of the discrepancies $\left(\mathrm{k}_{\mathrm{w}}=0,721, \mathrm{z}=36,13\right)$.

${ }_{14}$ An empty model only includes the dependent variable and partitions the variance between the two-levels (alter and network-level) without the inclusion of explanatory variables.
} 
significantly lower than those of the preceding proxy-reports on alters' preferences on immigration of Ethnic Germans $(p<0.01)$.

Table 3: Estimation of the influence of indicators of ego's information accessibility on the congruence of proxy-reports on immigration preferences ${ }^{15}$.

\begin{tabular}{|c|c|c|c|c|}
\hline & \multicolumn{2}{|c|}{ "Ethnic Germans" } & \multicolumn{2}{|c|}{ "Asylum-seekers" } \\
\hline General discussion & -0.34 & $(0.13)^{*}$ & -0.04 & $(0.13)$ \\
\hline Very relevant (ego) & -0.07 & $(0.22$ & -0.03 & \\
\hline very relevant (ego) $\mathrm{x}$ discussion & 0.66 & $(0.29)^{*}$ & -0.16 & $(0.27)$ \\
\hline Very dense network & 0.28 & $(0.13)^{*}$ & 0.24 & $(0.12)+$ \\
\hline Homogeneous network (actual attitudes) & 0.78 & $(0.20)^{* * *}$ & 0.50 & $(0.19)^{* *}$ \\
\hline Weekly contact & 1.78 & $(0.81)^{*}$ & 1.28 & $(0.67)+$ \\
\hline Close relation & 0.00 & $(0.5$ & 0.40 & $(0.53)$ \\
\hline Very close relation & 0.66 & $(0.55)$ & 0.90 & $(0.56)$ \\
\hline weekly $\mathrm{x}$ close & -1.50 & $(0.84)+$ & -0.79 & $(0.72)$ \\
\hline weekly $\mathrm{x}$ very close & -2.19 & $(0.86)^{*}$ & -1.42 & $(0.73)+$ \\
\hline Intercept & -0.70 & $(0.65)$ & -2.05 & $(0.65)^{* *}$ \\
\hline$\sigma_{\mathrm{u}}($ intercept variance $)$ & 0.54 & $(0.17)$ & 0.51 & $(0.16)$ \\
\hline$\rho$ (intraclass correlation) & 0.08 & $(0.05)$ & 0.07 & $(0.04)$ \\
\hline Log likelihood / Wald $\mathrm{Chi}^{2}$ & \multicolumn{2}{|c|}{$-979.84 / 80.60 * * *$} & \multicolumn{2}{|c|}{$-1028.27 / 58.96 * * *$} \\
\hline $\mathrm{N}_{\text {dyads }}\left(\mathrm{N}_{\mathrm{egos}}\right)$ & \multicolumn{2}{|c|}{$1564(842)$} & \multicolumn{2}{|c|}{$1557(833)$} \\
\hline \multicolumn{5}{|c|}{ Notes: $+p<0.10, * p<0.05, * * p<0.01, * * * p<0.001$} \\
\hline \multicolumn{5}{|c|}{$\begin{array}{l}\text { Results of two-level random intercept logistic models, using xtlogit-procedure of STATA. } \\
\text { Only the relevant coefficients for ego's information accessibility are displayed. The } \\
\text { analyses are controlled for: (a) no. of follow-ups; (b) missing information on homogeneity } \\
\text { and density; (c) reported network homogeneity according to the average of both proxy- } \\
\text { reports; (d) duration of relationship; (e) relevance for alter; (f) net size; and (g) the above } \\
\text { mentioned three indicators of ego's motivation: wrong contact information(s); missing data } \\
\text { on "sense of nationality"; nomination rank of alter. }\end{array}$} \\
\hline
\end{tabular}

As we can see from the estimated coefficients, the data do not support hypothesis 1. Even if, as expected, for the first proxy-report higher attention to the topic moderates the influence of direct information exchange. But, the estimated influence of the discussions on immigrants in general is negative. Additionally, these determinants have no impact on the accuracy of the second proxy-report. These surprising results require further investigation.

According to the coefficients concerning the relational characteristics, the opportunities to gain access to information about alter measured by the frequency of contact has a certain impact on the probability of congruent responses, but - as expected - it is moderated by the emotional closeness to the specific person. As regards the first proxy-report, the direct effect of frequency on the congruence is

15 The two-level logistic random intercept models were calculated by using the STATAprocedure $x$ tlogit with the reporting egos as indicators of the group level. The complete regression output is presented in the Appendix B1. 
statistically ensured. By contrast, a direct influence of closeness on the probability that ego will report accurately is not detected. Along with the negativ moderating effects regarding (very) close ties, these results support the assumption that the closeness cannot be treated as an additional indicator for a higher access to information. For the second proxy-report, the estimated parameters are not statistically significant, but indicate the same relation. Hypothesis 2 is completely confirmed only with regard to the first proxy-report.

In contrast, attitudinal homogeneity with respect to the actual attitudes of alters strongly affects the probability that ego reports accurately on the opinions of her/his reference persons, even if it is controlled for ego's perception of attitudinal homogeneity of her/his core network. Additionally, high network density increases the probability of congruent responses, even though this effect is apparently smaller. For the second proxy-report, this effect is only significant at a $10 \%$ level. Nevertheless, the effects indicate that ego's knowledge of alter's attitude is not only affected by the direct information exchange with alter, but also depends on the structure of her/his network. These results mostly confirm hypothesis 3 which is based on the assumption that the density and attitudinal homogeneity among the alters determine ego's opportunity to obtain information about alter caused by the information flow within the reference setting.

What can be used to compare the relative explanatory power of the indicators, is the likelihood ratio test (LRT), a method to assess the improvement in the goodness-of-fit between two models based on maximum likelihood estimation. ${ }^{16}$ According to these tests, the congruence of the first proxy-report on alter's preference on immigration of Ethnic Germans is mostly influenced by the characteristics of the network $\left(\operatorname{LR} \operatorname{chi}^{2}(5)=21.75\right)$. Thereby, the impact of the actual homogeneity is more important $\left(\mathrm{LR} \mathrm{chi}^{2}(2)=15.23\right)$. Density only improves the model fit if ego's perception of the attitudinal homogeneity is not controlled for. Besides these factors, direct information exchange indicated by "relevant discussions" (LR chi $\left.{ }^{2}(3)=12.08\right)$ as well as by the characteristics of the relationship ( $\left.\mathrm{LR} \mathrm{chi}^{2}(5)=11.38\right)$ have a significant impact on the congruence. Ego's motivation to answer correctly is also relevant $\left(\operatorname{LR}\right.$ chi $\left.^{2}(4)=10.76\right)$.

For the second proxy-item, the results of the LRT are very different. Ego's motivation to answer correctly $\left(\operatorname{LR} \operatorname{chi}^{2}(4)=15.47\right)$ has the highest impact on the congruence with respect to the proxy-report. With regard to ego's access to information, only the network homogeneity has a significant influence on the congruence $\left(\mathrm{LR} \mathrm{chi}^{2}(2)=6.64\right)$. Compared with this, the direct information exchange has hardly any influence; such an influence can neither be observed for discussions, nor for the intensity of the contact. These results of the relatively weak impact of ego's information accessibility hints that the second proxy-report was based less on information about the specific alters.

16 To calculate the likelihood-ratio-test, the substantive indicators as well as the relevant control variables were excluded from the restricted model. 


\subsection{A problematic result}

The most astounding finding of the models explaining congruence is the one concerning the influence of discussions on "immigrants in Germany". According to the data, conversations about a topic related to the attitude in question do not increase the congruence under all circumstances. For the second proxy-report, discussions about "immigrants" seem to have no influence at all. Even more, the model for ego's first report on alter's attitude referring to Ethnic Germans from Eastern Europe indicates a significant, negative direct effect of information exchange between ego and alter. When controlled for ego's report on the relevance of the topic, it suggests that ego would be less likely to report alter's attitude in the same way as alter did if "immigrants in Germany" was a topic of joint discussions in the last six months than if the ego didn't talk about it with her/his communication partner. Only if ego considered the topic "foreigners" as a very relevant topic, a higher congruence would be predicted.The corresponding conditional effect plot $^{17}$ is displayed in Figure 3.

According to hypothesis 1, no descending line was expected. Therefore, even if the expected moderating effect of the relevance of the topic is observed, the results do not confirm this hypothesis. Moreover, these results contradict other empirical findings in this respect (e.g. Chen, 1999; Menon et al., 1995; Sudman et al., 1996).

However, recourse to assumptions on the particularities of forming proxyreports and the structure of memory could provide a possible alternative explanation (Chen, 1999; Schwarz and Wellens, 1994). According to both, a distinction should be made between substantively related general dispositions and specific attitudes considering features of the attitude objects. It is assumed that if ego perceived a general disposition of alter but did not have access to specific information, ego would probably form her/his report on alter based on the perceived or assumed general disposition of alter (cf. Chen, 1999).

Taking into account this hierarchy of knowledge, the results concerning hypothesis 1 could be explained assuming that the preferences on immigration represent specific aspects of the general attitude towards foreigners. While the indicator "discussions" does not consider this differentiation, it remains unclear to which extent this variable indicates a better access to information about the preferences on immigration concerning different groups of people.

\footnotetext{
17 The estimated probabilities were calculated based on the results presented in Appendix B1, model "Ethnic Germans", including the other indicators fixed at their mean, respective at the more frequent value. An average dyad is characterized by the following features: net size $=4$; number of follow-up-interviews $=2$; nomination rank $=1$; close relationship existing for 20 years; weekly contact; very dense network, actually as well as perceived homogeneous in respect of the preferences on immigration; no missing report on "sense of nationality" and no false contact information.
} 


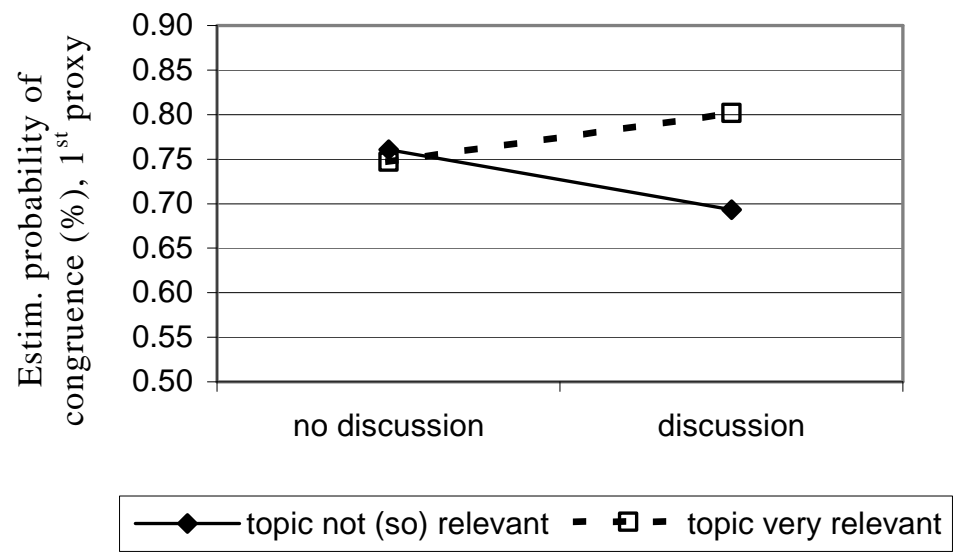

Figure 3: Conditional effect plot: The influence of direct discussions about "immigrants in Germany" on the congruence with respect to the first proxy-item moderated by the "relevance of the topic" reported by ego.

With regard to our results, we assume that by remembering substantively related discussions but not retrieving specific information means that ego's responses are based to a greater extent on the perceived general disposition of alter towards immigrants. Thus, ego's proxy-reports on alter's preferences on immigration are more stereotypic; they will differentiate less between the preferences concerning Ethnic Germans or Asylum-seekers. Consequently, under these circumstances concordant responses are less probable because alter's reports on her/his preferences on immigration will show a higher level of differentiation. First supporting evidence comes from the observed correlation between both proxy-reports. Both proxy-reports concerning alters with whom ego discussed the topic of immigrants show - as expected - a higher correlation (Kendall's tau$b=0.54$ ) than those of dyads without such communication (Kendall's tau-b=0.44). However, to further test this modified hypothesis on the influence of joint discussions about immigrants, the previous approach to explaining congruence is not sufficient.

\subsection{Proxy-reports explained}

In the following section we consider to what extent ego's proxy-reports on alter's attitudes can be explained by ego's own attitudes or by the actual attitudes of the alters depending on ego's information accessibility. As presented in Figure 2, the dependent variable is each proxy-report. As measures of ego's and alter's attitudes towards immigrants, both self-reported indexes can be included in the analyses. According to our hypotheses, the proxy-reports are expected to be influenced more by alter's attitudes and less by ego's attitudes when the respondent had access to more information about alter's attitudes. Interaction variables calculated between 
the indicators of ego's information accessibility based on direct and indirect communication, on the one hand, and alter's as well as ego's attitudes, on the other, should prove to have a statistically significant moderating impact. The dependent as well as the independent attitudinal variables are included in $\mathrm{z}$ standardized form into the regression models.

Table 4: Explaining the proxy-reports by the self-reported attitudes of ego and alter.

\begin{tabular}{lcc}
\hline & $\begin{array}{c}\text { Ethnic Germans } \\
\text { Coeff }(\mathrm{z})\end{array}$ & $\begin{array}{c}\text { Asylum-seekers } \\
\text { Coeff }(\mathrm{z})\end{array}$ \\
\hline $\begin{array}{l}\text { ego's self-reported attitudes } \\
\text { general attitude towards immigrants }\end{array}$ & $-0.01(-0.38)$ & $0.02(0.88)$ \\
specific immigration preferences & $0.43(14.51)^{* * *}$ & $0.49(16.46)^{* * *}$ \\
alter's self-reported attitudes & & \\
general attitude towards immigrants & $0.14(5.60)^{* * *}$ & $0.15(6.47)^{* * *}$ \\
specific immigration preferences & $0.08(3.36)^{* *}$ & $0.02(1.03)$ \\
\hline Intercept & $0.14(0.58)$ & $0.00(0.00)$ \\
\hline$\sigma_{\mathrm{u}}$ (intercept variance) & 0.64 & 0.53 \\
$\sigma_{\mathrm{e}}$ (slope variance) & 0.71 & 0.61 \\
$\rho($ intraclass correlation) & 0.30 & 0.43 \\
\hline $\mathrm{R}^{2}-$ overall / Wald-Chi ${ }^{2}$ & $0.27 / 430.40^{* * *}$ & $0.31 / 526.11^{* * *}$ \\
\hline $\mathrm{N}_{\mathrm{dyad}} / \mathrm{N}_{\mathrm{ego}}$ & $1546 / 832$ & $1532 / 822$ \\
\hline Notes: ${ }^{*} \mathrm{p}<0.05, * * \mathrm{p}<0.01, * * * \mathrm{p}<0.001 ;$ & \\
$\quad$ The dependent as well as the independent variables are z-standardized. Results of two- \\
$\quad$ level random intercept linear regression models, using xtreg-procedure of STATA.
\end{tabular}

The regression models shown in Table 4 estimate the impact of ego's and alter's attitudes towards immigrants on both proxy-reports without considering the moderating factors. The results show a high impact of ego's preferences on immigration on both proxy-reports. In addition, the findings confirm the assumption that proxy-reports generally rely to a greater degree on alter's general disposition than on alter's specific attitude in question. But, contrasting the estimated coefficients of the attitudes as well as their explanatory power in each model tested by using the Wald-Chi ${ }^{2}$-test, it becomes obvious that the second proxy-report is influenced by alter's self-reports to a lesser degree than the first one. This fact is illustrated by the reduction of the overall- $\mathrm{R}^{2}$ when alter's attitudes indexes are removed from the regression equations: Removing both reports of alter, the explained deviance would be reduced by 3.9 percentage points concerning the first proxy-report, but only by 2.8 percentage points concerning the second one. As far as the second proxy-report reflects alter's attitude it relies to a lesser degree on alter's specific preferences on immigration than on her/his general attitude towards immigrants compared to the estimations concerning ego's first report on alter's attitude. Moreover, as can be seen in Table 4, on average alter's 
specific attitude is found to have no impact at all on the second proxy-report when ego's self-reports are controlled for. These results support the conclusion drawn from the findings of the congruence analyses that ego's responses to the second proxy-item are formed less specific to each alter.

Table 5: Moderating factors by explaining proxy-reports by actual attitudes, controlling for moderating factors of ego's information accessibility.

\begin{tabular}{|c|c|c|}
\hline & Ethnic Germans & Asylum-seekers \\
\hline & Coef. (S.E.) & Coef. (S.E.) \\
\hline preferences on immigration (alter) & $-0.08(0,06)$ & $-0.05(0.05)$ \\
\hline * high dense network & $0.12(0.05)^{*}$ & \\
\hline * actual homogeneous net & $0.25(0.06)^{* * *}$ & $0.13(0.06)^{*}$ \\
\hline general attitude towards immigrants (alter) & $0.03(0.06)$ & $0.07(0.06)$ \\
\hline$*$ general discussion & $0.12(0.05)^{*}$ & \\
\hline$*$ very close and weekly contact ${ }^{(1)}$ & $0.06(0.03)^{*}$ & $0.12(0.05)^{*}$ \\
\hline preferences on immigration (ego) & $0.40(0.06)^{* * *}$ & $0.55(0.05)^{* * *}$ \\
\hline$*$ actual homogeneous net & & $-0.16(0.06)^{* *}$ \\
\hline Intercept & $0.02(0.08)$ & $-0.07(0.08)$ \\
\hline$\sigma_{\mathrm{u}}($ intercept variance $)$ & 0.45 & 0.54 \\
\hline$\sigma_{\mathrm{e}}($ slope variance $)$ & 0.70 & 0.60 \\
\hline$\rho$ (intraclass correlation) & 0.29 & 0.44 \\
\hline $\mathrm{R}^{2}$ - overall / Wald-Chi ${ }^{2}$ & $0.29 / 500.09 * * *$ & $0.33 / 579.42 * * *$ \\
\hline $\mathrm{N}_{\text {dyade }}\left(\mathrm{N}_{\mathrm{eg} \mathrm{o}}\right)$ & $1553(837)$ & $1541(829)$ \\
\hline \multicolumn{3}{|c|}{$\begin{array}{l}\text { Notes: }{ }^{*} \mathrm{p}<0.05, * * \mathrm{p}<0.01, * * * \mathrm{p}<0.001 ; \text { (ego) ego's self-report; (alter) alter's self-reports. } \\
{ }^{(1)} \text { This dummy indicates a very close relationship with at least weekly contact between eg } \\
\text { and alter opposite to all other ties. Results of two-level random intercept linear regressior } \\
\text { models, using xtreg-procedure of STATA. Only the significant coefficients of interaction } \\
\text { effects are displayed (cf. Appendix B2, models M1). }\end{array}$} \\
\hline
\end{tabular}

The estimations of the regression models including the moderating factors of ego's information accessibility are presented in Table 5. Only the significant moderating effects concerning the controlled determinants of ego's information accessibility are listed with respect to the moderated attitude; the complete regression outputs are presented in Appendix B2, models M1. The coefficients of the moderating effects are directly contrastable due to the fact that all moderating factors are restricted to values between 0 and 1 , operationalized either as continuous or dichotomous variables. In order to reduce the degrees of freedom, the influence of ego's general attitude towards immigrants was neglected in the analyses. The basic models, presented above, indicated that ego's general disposition did not directly affect the variation of the proxy-reports. The different opportunities to access information about alter are operationalized using the variables "high density" and "actual attitudinal homogeneity" on the network level 
and "discussion" as well as a dummy variable counting for a very close relationship with at least weekly contact on the dyadic level.

According to the results, the indicators of ego's information accessibility included in the regression models moderate the influence of the attitudes to different degrees. But as far as they concern alter's attitudes, all statistically significant moderating effects have positive estimated coefficients. This means that, as expected, the used operationalizations actually indicate a higher influence of ego's knowledge of alter on ego's proxy-report, but different attitudes of alter were increasingly considered.

Both moderators concerning the direct communication between ego and alter influence the extent to which ego's proxy-reports reflect the general disposition of alter. They seem to not affect ego's use of a more differentiated knowledge of alter's specific attitude. Proxy-reports on attitudes of alters to whom ego has at least weekly contact and to whom he/she feels very close to are based on alter's attitudes to a higher degree than proxy-reports on attitudes of alters to whom ego is less intensely related. Hence, the respondents base their proxy-reports rather on alter's general disposition than on alter's specific attitude. ${ }^{18}$ Similarly, concerning the first proxy-report, remembering substantively related discussions the proxyreport reflects more the general disposition of alter than if these discussions are not recalled. ${ }^{19}$

By contrast, both indicators of ego's information accessibility based on the network, the density and attitudinal homogeneity, have a moderating effect on the influence of alter's specific attitude towards immigrants. Again, the suggested influence is higher in the estimated model concerning the first proxy-report. However, the actual homogeneity has the highest moderating effect among all considered indicators. A particularity of this moderator variable is the fact that the influence on alter's specific attitude is less concerning the proxy-report on Asylum-seekers, while simultaneously a moderating effect on the impact of ego's own attitude is suggested.

Overall, the extension of the models proves to increase the model fit significantly according to the Wald-Chi ${ }^{2}$-tests. The estimated moderating effects even remain the same when the attitudinal homogeneity perceived by ego is additionally considered (cf. Appendix B2, models M2).

${ }^{18}$ The separate impacts of the frequency of contact or of the closeness has been tested but no statistically significant moderating effect proved to be related to one of the attitudes.

${ }^{19}$ The impact of the relevance of the topic for ego has been tested (results not reported). Significant moderating effects have been observed in models only considering hypothesis 1 , supporting that modification of the hypothesis. But in the multivariate models an additional impact did neither prove to be significant nor seems to change the interpretation. 


\section{Summary and conclusions}

Ego-centric network analyses are a fertile approach to consider the social embeddedness of actors in the explanation of sociologically interesting phenomena using social survey data. Mostly for pragmatic reasons, data on ego-centric networks only include ego's point of view of the network and the traits of the related alters. Often treated as approximately actual features of the alters, this proxy information is typically used for analyzing the impact of the characteristics of the personal reference setting. However, if more than ego's perception of her/his social environment is of analytical interest, this practice can be misleading. Given that respondents have difficulties in answering attitudinal questions for themselves, proxy information on attitudes of other persons is especially precarious.

Assessing the quality of proxy-reports on attitudes, the most important criterion of "accuracy" is alter's report on her/his own attitude. According to our results, the "accuracy" of proxy-reports on alter's attitude towards immigrants is conditional on characteristics of the dyads as well as of the whole network these dyads are embedded in. First, egos in dense and actual homogeneous networks with respect to the attitude were significantly more able to report alter's attitudes "correctly". Second, the frequency of contact and the emotional closeness have been found to affect the "accuracy" of the proxy-reports as well, but they can't be generally interpreted as additive indicators of higher information accessibility. The emotional distance to the alter in question moderates the extent to which frequent contact enhances the probability of the respondent reports being more "accurate". Third, communicating about immigrants in Germany does not enhance the congruence of proxy-reports on alter's attitude towards immigrants. Remembering joint discussions on a topic appears to sometimes result in less accurate reports, at least when using a question-wise organized questionnaire.

For a better understanding of the results of the congruence analysis, a second approach to assess the quality of ego's proxy-reports is used: the analysis of the extent to which the proxy-reports can be explained by ego's own attitudes or by the actual attitudes of the alters. In terms of data quality, the question is under which circumstances proxy-reports rely to a higher degree on alter's actual attitudes. It can thus be derived, without regard to the congruence, which kind of attitudes of alter is more related to the proxy-reports.

Using this approach, the results point out the high impact of ego's specific attitude. According to our data, the proxy-reports additionally rely to a greater degree on alter's substantively related general disposition than on alter's specific attitude in question. Proxy-reports show a lower degree of differentiation, at least concerning similar attitude objects, due to less information being available on specific attitudes, to anchoring in the general disposition of alter, and to susceptibility to question order effects. Consequently, the average of proxy-reports on alter's preferences on immigration is a significantly better predictor of alter's 
actual general attitude towards immigrants $\left(\mathrm{R}^{2}=0,115\right)$ than of alter's actual preferences on immigration $\left(\mathrm{R}^{2}=0,07\right)$. Unfortunately, it could not be tested to which degree asking directly for the general disposition of alter would result in a higher predictive power of the proxy-reports.

Furthermore confirming the results of the congruence analysis, the indicators of information accessibility moderate the impact of alter's actual attitudes. The findings suggest that the indicators of the opportunities of direct information exchange between ego and alter are related to the extent to which the proxy-reports reflect the general disposition of the alters. When ego and alter are tied to each other within a very close relationship with at least weekly contact or when both have communicated about a substantively related question, the proxy-reports reflect to a greater extent the general disposition of the alters, but the impact of their specific attitude in question remains marginal. By contrast, both indicators of ego's information accessibility based on the network structure seem to moderate the impact of alter's actual specific attitude. The proxy-reports of respondents possessing a dense or actually attitudinal homogeneous network reflect the specific attitude of the alters to a higher degree.

A better understanding of the quality of proxy information is not only relevant to egocentric network data but also to missing data imputation in complete networks. Despite the notable limitations of this study, such as the lack of comparisons with proxy-reports on other attitudes, the restricted measurement level of the proxy-reports analyzed, and the unmeasured relevance of the attitude with respect to each particular tie, three conclusions can be drawn for collecting data about alter's attitudes using proxy-reports. First, because of their specific character, social network questions should be developed very carefully. Although this is not particularly addressed in this paper, it should be highlighted that proxyreporters are much more susceptible to response effects or social desirability. Especially proxy-reports concerning alter's attitudes are threatened by such biases. As can be seen when comparing the results for both proxy-reports, the second proxy was less accurate and referred less to a certain alter. Second, the results indicate that proxy-reporting may be a reasonable instrument for gathering informative data on attitudinal dispositions of alters, understanding the data as approximations. However, specific attitudes are rarely captured by proxy-reports. Thus, it is recommended that for the collection of attitudinal data by means of proxy-reports the name interpreter items should refer to general dispositions. Otherwise, follow-up interviews with the alters have to be conducted. In summary, the results of our analyses point out that social network analysis in general has to distinguish analytically and - as far as possible - empirically between alters' attitudes reported by ego and the attitudes of alters reported by themselves. 


\section{Acknowledgement}

The author would like to thank Patrick Schupp and Thorsten Kneipp for their valuable comments and their patience. This study was carried out in the context of the research project "Ethnic Cleavages and Social Contexts II" founded by the Volkswagen Foundation.

\section{References}

[1] Alba, R.D., Schmidt, P.J., and Wasmer, M. (2004): Germans or Foreigners? Attitudes Toward Ethnic Minorities in Post-Reunification Germany. New York: Palgrave Macmillan.

[2] Barnes, J. (1979): Network Analysis: Orienting Notion, rigorous technique, or substantive field of study? In Holland, P.W. and Leinhardt, S. (Eds.): Perspectives on social network research, 25-50. New York: Academic Press.

[3] Becker, B. (2005): Der Einfluss der Bezugsgruppenmeinung auf die Einstellung gegenüber Ausländern in Ost- und Westdeutschland. Zeitschrift für Soziologie, forthcoming.

[4] Bickart, B., Menon, G., Schwarz, N., and Blair, J. (1994): The use of anchoring strategies in constructing proxy reports of attitudes. International Journal of Public Opinion Research, 6, 375-379.

[5] Burt, R.S. (1984): Network items and the General Social Survey. Social Networks, 6, 239-339.

[6] Chen, K.K. (1999): The methodology of networks proxy-reporting: How well do respondents proxy-report different kinds of information on others, and how do respondents err in making these proxy-reports. Unpublished manuscript, Qualifying Paper, Harvard University.

[7] Cohen, J. (1960). A coefficient of agreement for nominal scales. Educational and Psychological Measurement, 20, 37-46.

[8] Conway, M.A. (1992): A structural model of autobiographical memory. In Conway, M.A., Rubin, D.C., Spinnler, H., and Wagenaar, W.A. (Eds.): Theoretical Perspectives on Autobiographical Memory, 167-194. Dordrecht: Kluwer academic.

[9] Erickson, B.H. (1988): The relational basis of attitudes. In Wellmann, B. and Berkowitz, S.D. (Eds.): Social Structures: A Network Approach. Cambridge: Cambridge Univ. Press.

[10] Ganter, S. (2003): Soziale Netzwerke und interethnische Distanz. Theoretische und empirische Analysen zum Verhältnis von Deutschen und Ausländern. Wiesbaden: Westdeutscher Verlag.

[11] Goldstein, H. (1995): Multilevel Statistical Models, 2. ed. London: Arnold. 
[12] Goodman, L.A. (1961): Snowball sampling. The Annals of Mathematical Statistics, 21, 148-170.

[13]Harkness, J. and Haarmann, A. (2004): German General Social Survey 2004. English Translation of the "ALLBUS"-Questionnaire. (ZUMA-Methodenbericht 2004/02). Mannheim: Zentrum für Umfragen, Methoden und Analysen.

[14]Jäger, A. (2004): Forschungsprojekt Ethnische Grenzziehung und soziale Kontexte II: Methodenbericht. Mannheim: MZES.

[15] Kogovšek, T., Ferligoj, A., Coenders, G., and Saris, W.E. (2002): Estimating the reliability and validity of personal support measures: Full information ML estimation with planned incomplete data. Social Networks, 24, 1-20.

[16] Kojetin, B.A. and Mullin, P. (1995): The quality of proxy reports on the current population survey (CPS). Paper presented at the 50th Annual Conference of the American Association for Public Opinion Research, May 18-21, 1995, Fort Lauderdale, Florida.

[17] Kreuter, F., Maaz, K., and Watermann, R. (2004): Validität von Schülerangaben zum sozioökonomischen Status der Eltern in der PISA - Studie. Paper presented at the $32^{\text {nd }}$ congress of the German Sociological Assocation $(G S A)$, October $4^{\text {th }}$ to $8^{\text {th }}, 2004$, München, Germany, on October the $6^{\text {th }}, 2004$.

[18]Landis, J.R. and Koch, G.G. (1977): The measurement of observer agreement for categorical data. Biometrics, 33, 159-174.

[19]Laumann, E.O., Marsden, P.V., and Prensky, D. (1989): The boundary specification problem in network analysis. In Freeman, L.C., White, D.R., and Romney, A.K. (Eds.): Research Methods in Social Network Analysis, 67-87. New Brunswick, New Jersey: Transaction Publishers.

[20] Marsden, P.V. (1987): Core discussion networks of Americans. American Sociological Review, 52, 122-131.

[21] Marsden, P.V. (1990): Network data and measurement. Annual Review of Sociology, 16, 435- 463.

[22] Menon, G., Bickart, B.A., Blair, J., and Sudman, S. (1995): How well do you know your partner? Strategies for formulating proxy-reports and their effects on convergence to self-reports. Journal of Marketing Research, 32, 75-84.

[23] Moore, J.C. (1988): Self/ proxy response status and survey response quality. A review of the literature. Journal of Official Statistics, 4, 155-172.

[24] Newman, M.E.J. (2003): Ego-centered networks and the ripple effect. Social Networks, 25, 83-95.

[25]Pappi, F.U. (1996): Personal environments in the process of political intermediation as a topic of the comparative national election study. In Hayashi, C. and Scheuch, E. (Eds.): Quantitative Social Research in Germany and Japan, 122-139. Opladen: Leske + Budrich. 
[26]Pappi, F.U. (1998): Soziale Netzwerke. In Schäfers, B. and Zapf, W. (Eds.): Handwörterbuch zur Gesellschaft Deutschlands, 584-596. Opladen: Leske + Budrich.

[27]Pappi, F.U. and Wolf, G. (1984): Wahrnehmung und Realität sozialer Netzwerke. Zuverlässigkeit und Gültigkeit der Angaben über beste Freunde im Interview. In Meulemann, R. and Reuband, K. (Eds.): Soziale Realität im Interview, 281-300. Frankfurt am Main: Campus.

[28]Pfenning, A., Mohler, P.Ph., and Pfenning, U. (1991): Zur Reliabilität von egozentrierten Netzwerken in Massenumfragen. ZUMA-Nachrichten, 28, 92-108.

[29]Rice, R.E. and Aydin, C. (1991): Attitudes toward new organisational technology: Network proximity as a mechanism for social information processing. In Administrative Science Quarterly, 36, 219-244

[30] Schwarz, N. and Wellens, T. (1994): Cognitive dynamics of proxy responding. The diverging prespectives of actors and observers. U.S. Census Bureau SM94/07.

[31] Scott, J. (1991): Social Network Analysis. A Handbook. London: Sage.

[32] Skowronski, J.J., Betz, A.D., Thompson, C.P., Walker, W.R., and Shannon, L. (1994). The impact of differing memory domains on event-dating processes in self and proxy reports. In Sudman, S. and Schwarz, N. (Eds.): Autobiographical Memory andThe Validity of Retrospective Reports, 217-231. New York: Springer.

[33] Snijders, T.A.B. and Bosker, R.J. (1999): Multilevel Analysis. An introduction to basic and advanced multilevel modelling. London: SAGE Publications.

[34] Stocké, V. (2003): Measuring Information Accessibility and Predicting Response-Effects: The Validity of Response-Certainties and Response-Latencies. Publications 03-25. Sonderforschungsbereich 504, University of Mannheim.

[35] Sudman, S., Bradburn N., and Schwarz, N. (1996): Thinking about Answers. The Application of Cognitive Processes to Survey Methodology, Chapter 10: Proxy-reporting, 227-243. San Francisco: Jossey-Bass.

[36] Todorov, A., and Kirchner, C. (2000): Bias in proxies' reports of disability: Data from the National Health Interview Survey on disability. American Journal of Public Health, 90, 1248-1253.

[37] Tourangeau, R., Rips, L.J., and Rasinski, K.A. (2000): The Psychology of Survey Response. Cambridge: Cambridge Univ. Press.

[38] Wasmer, M., Koch, A., Harkness, J., and Gabler, S. (1996): Konzeption und Durchführung der „Allgemeinen Bevölkerungsumfrage der Sozialwissenschaften “ (ALLBUS). (ZUMA-Arbeitsbericht 96/08). Mannheim: Zentrum für Umfragen, Methoden und Analysen (ZUMA).

[39] Wasserman, S. and Faust, K. (1994): Social Network Analysis: Methods and Applications. Cambridge: Cambridge Univ. Press. 
[40] Wellman, Barry (1988): Structural analysis. From method and metaphor to theory and substance. In Wellman, B. and Berkowitz, S. (Eds.): Social Structures. A Network Approach, 15-61. Campridge: Campridge University Press.

[41] White, K. and Watkins, S.C. (2000): Accuracy, stability and reciprocity in informal conversational networks in rural Kenya. Social Networks, 22, 337-355.

\section{Appendix}

\section{Appendix A: Question wording}

\section{A.1: Name generator}

F89: From time to time, most people discuss important personal matters with other people. Looking back over the last six months, who are the people with whom you discussed matters important to you?

These could be very different people, for instance, friends, relatives, colleagues, neighbors etc. Just tell me the names or initials of the persons with whom you discussed important matters. Please, nominate the five most important persons.

[up to five names]

\section{A.2: Name interpreter used in this study}

The following questions all refer to nominated persons identified with name generator question F89.

F93_X: How many years have you known [person X]?

[years]

F95_X: How close do you feel to [person X] at present/the moment?

[very close - close - not so close]

F97_X: Typically, how often did you talk to [person X] in the last six months?

[nearly every day - several times a week - once a week - every month - less often never]

F98_X: There are several topics about which people converse sometimes/occasionally. Looking back over the last six months, about which topics did you talk with the nominated persons? I will tell you some issues, so you just have to answer yes or no.

Did you talk to [person X] about "job and career" - "partnership matters" - "TV program" - "political issues" - "relation between Germans and immigrants" "sports" - "financial affairs")?

[multiple answers: yes - no] 
F99_X: A short while ago we talked about different opinions on the immigration of Ethnic Germans from EasternEurope and Asylum-seekers.

Please tell us about [person X]'s opinion about this issue? Acording to her/his opinion, should the immigration of Ethnic Germans from Eastern Europe be ...

[unrestrictedly possible -restricted - completely stopped]

F100_X: What do you think, does [person X] mean that the immigration of Asylumseekers has to has to be .. ? According to [person X]'s opinion, should immigration of Asylum-seekers be ...

[unrestrictedly possible -restricted - completely stopped]

F102_XY: Finally, I would like to know whether the nominated persons know each other - regardless how often they met each other.

Do [person X] and [person Y] know each other personally?

[yes - no]

F103_XY: [If yes] Do [person X] and [person Y] know each other ..?

[well - rather sketchy]

\section{A.3: Relevant self-reports}

F12_A(-F): According to your opinion which are currently the most important political or social issues at your place of residence? I will just tell you some topics which are discussed in public again and again? Please tell me how important you consider these issues according to your personal point of view.

How important do you consider the issue $(A)$ "jobs" ((B) “cultural opportunities" - $(C)$ "foreigners" - (D) "situation on the housing market" - $(E)$ "traffic situation" - $(F)$ "environmental situation") at your place of residence? [question order was randomized] [very important - important - less important - unimportant]

F47_A(-D): Now, I will quote some statements on foreigners living in Germany, which you presumably also have heard at one time or another. Please tell me for each statement to what extent you agree with it.

(A) "Foreigners living in Germany should adapt their way of life a bit more closely to the German way of life." (B) "When jobs get scarce, foreigners living in Germany should be sent home again." (C) "Foreigners living in Germany should not be allowed to take part in any kind of political activity." (D) "Foreigners living in Germany should only marry people of their own nationality."

[agree - rather agree -rather disagree - disagree]

F72-F75: Currently, the immigration of various groups of people into Germany is frequently discussed in politics. What is your opinion about the immigration of (F72) "Ethnic Germans from Eastern Europe" [(F73) "Asylum-seekers" - (F74) "people from EU countries coming to work here" - (F75) "people from non-EU countries, e.g. Turkey, coming to work here"]? Do you think that the immigration of those persons should be..?

[unrestrictedly possible -restricted - completely stopped] 


\section{Appendix B: Results of multivariate regression models}

Table B1: Estimations of the influence of indicators of ego's information accessibility on the congruence of proxy-reports on immigration preferences.

\begin{tabular}{|c|c|c|}
\hline & $\begin{array}{c}\text { "Ethnic Germans" } \\
\text { Coeff. (S.E.) }\end{array}$ & $\begin{array}{c}\text { "Asylum-Seekers" } \\
\text { Coeff. (S.E.) }\end{array}$ \\
\hline general discussion (1) (4) & $-0.34(0.13)^{*}$ & $-0.04(0.13)$ \\
\hline very relevant (ego) (1) (4) & $-0.07 \quad(0.22)$ & $-0.03(0.21)$ \\
\hline (i) very relevant (ego) $\mathrm{x}$ discussion & $0.66(0.29)^{*}$ & $-0.16(0.27)$ \\
\hline C:very relevant (alter) (1)(4) & $-0.14(0.14)$ & $-0.24(0.14)+$ \\
\hline weekly contact $^{(1)(3)}$ & $1.78(0.81)^{*}$ & $1.29(0.67)+$ \\
\hline $\operatorname{close}^{(1)(3)}$ & $0.00 \quad(0.52)$ & $0.40 \quad(0.53)$ \\
\hline very close ${ }^{(1)(3)}$ & $0.66(0.55)$ & $0.90(0.56)$ \\
\hline (i) close $\mathrm{x}$ weekly & $-1.51(0.84)+$ & $-0.80(0.72)$ \\
\hline (i) very close $\mathrm{x}$ weekly & $-2.19(0.86)^{*}$ & $-1.42(0.73)+$ \\
\hline C: duration of the relationship (years) & $-0.02(0.01)$ & $0.03(0.01)^{*}$ \\
\hline $\mathrm{C}$ : duration of the rel. (squ. years) & $0.00 \quad(0.00)$ & $0.00(0.00)+$ \\
\hline very dense ${ }^{(1)(5)}$ & $0.28(0.13)^{*}$ & $0.24(0.12)+$ \\
\hline C: missing density measure ${ }^{(1)}$ & $0.54 \quad(0.62)$ & $0.63(0.61)$ \\
\hline attitudinal homogeneous (actual) ${ }^{(5)}$ & $0.78(0.20)^{* * *}$ & $0.50(0.19)^{*}$ \\
\hline C: missing homogeneity measure ${ }^{(1)}$ & $0.64(0.25)^{*}$ & $0.33(0.24)$ \\
\hline false tel. numbers ${ }^{(1)(2)}$ & $-0.37(0.18) *$ & $-0.38 \quad(0.18)^{*}$ \\
\hline no. of telephone numbers ${ }^{(2)}$ & $0.38 \quad(0.40)$ & $-0.33(0.37)$ \\
\hline missing self-report "sense of nation." (1) (2) & $-0.08(0.26)$ & $-0.63(0.24)^{*}$ \\
\hline nomination rank of the alters ${ }^{(2)}$ & $-0.11(0.05)^{*}$ & $-0.10(0.05)^{*}$ \\
\hline C: net size & $0.05(0.07)$ & $0.22(0.07)^{* * *}$ \\
\hline C: attitudinal homogeneous (perceived) & $0.96(0.19)^{* * *}$ & $0.59(0.18)^{* *}$ \\
\hline C: missing homogeneity measure $(1)$ & $0.93(0.39)^{*}$ & $0.29 \quad(0.44)$ \\
\hline C: no. of realized follow-up-interviews & $0.06(0.08)$ & $-0.05(0.08)$ \\
\hline Intercept & $-0.69(0.65)$ & $-2.06(0.65)^{* * *}$ \\
\hline$\sigma_{\mathrm{u}}($ intercept variance $)$ & $0.54 \quad(0.17)$ & $0.52(0.16)$ \\
\hline$\rho$ (intraclass correlation) & $0.08 \quad(0.05)$ & $0.07(0.04)$ \\
\hline Log likelihood / Wald-Chi ${ }^{2}$ & $-979.8 / 80.6 * * *$ & $-1028.3 / 58.96^{* * *}$ \\
\hline $\mathrm{N}_{\text {dyads }}\left(\mathrm{N}_{\text {egos }}\right)$ & $1564(842)$ & $1557(833)$ \\
\hline
\end{tabular}

Notes: Significance: $+\mathrm{p}<0.10, * \mathrm{p}<0.05, * * \mathrm{p}<0.01, * * * \mathrm{p}<0.001$;

(i) multiplicative interaction terms, C: control variables, (1) Dummy variables with reference category "not applicable". Indicators refer to: (2) ego's motivation to answer correctly. (3) ego's information accessibility due to traits of the tie. (4) ego's information accessibility due to discussions. (5) ego's information accessibility due to traits of the network. 
Table B2: Estimations of the influence of moderating factors on explaining proxyreports by actual attitudes.

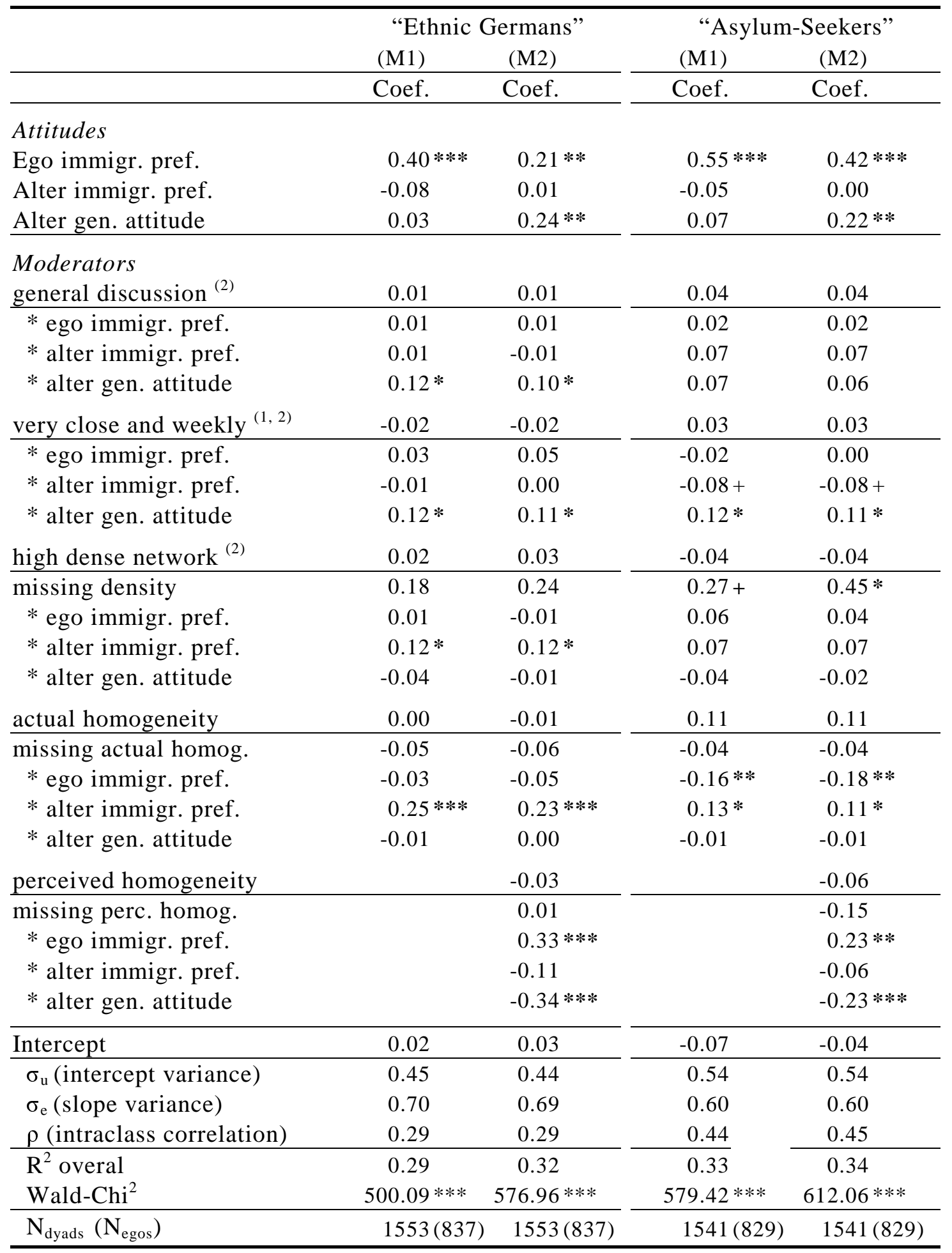

Notes: Significance: $+\mathrm{p}<0.10, * \mathrm{p}<0.05, * * \mathrm{p}<0.01, * * * \mathrm{p}<0.001 ;$.

Models M2 repeat the regression equation from M1 including the control variables "perceived attitudinal homogeneity". "immigr. pref": = index on preferences on immigration; "gen. attitude": = general attitude towards immigrants. (1) This dummy indicates a very close relationship with at least weekly contact between ego and alter opposite to all other ties. (2) Dummy variables with reference category "not applicable" 